\title{
A Study on the Pitting Initiation of Duplex Stainless Steel (DSS 2205) Welded Joints Using SEM-EDS, SKPFM and Electrochemistry Methods
}

\author{
Jiakun Sun ${ }^{1}$, Xiaolei $L^{2}$, Yangting Sun ${ }^{1}$, Yiming Jiang ${ }^{1}$, Jin $i^{1, *}$ \\ ${ }^{1}$ Department of Materials Science, Fudan University, Shanghai 200433, China \\ ${ }^{2}$ The Center of Analysis and Measurement, Fudan University, Shanghai 200433, China \\ *E-mail: corrosion@fudan.edu.cn
}

doi: $10.20964 / 2018.12 .54$

Received: 10 August 2018 / Accepted: 3 October 2018 / Published: 5 November 2018

\begin{abstract}
The influence of laser beam welding and a subsequent short-time post-weld heat treatment on the pitting corrosion in duplex stainless steel was investigated by diverse techniques, including the polarization curve method, scanning electron microscopy-energy dispersive spectroscopy, scanning Kelvin probe force microscopy and optical microscopy. It was found that for as-welded specimens, the fused zone was the preferential pit initiation site. The Volta potential maps for the laser beam welded samples revealed that some low potential areas emerged inside the ferrite phases, which may be considered as preferential nucleation sites for the pitting corrosion. The pit morphologies showed that the pits were generated in areas with a lower surface potential value. After a 3 min post-weld heat treatment at $1080^{\circ} \mathrm{C}$, the reduction in the surface potential differences indicated that the corrosion resistance of laser welded joints was restored, and the low potential areas that indicated the chromium depleted regions around the $\mathrm{Cr} 2 \mathrm{~N}$ disappeared..
\end{abstract}

Keywords: Duplex stainless steels; Laser beam welding; SKPFM; Volta potential; Pitting corrosion

\section{$\underline{\text { FULL TEXT }}$}

(C) 2018 The Authors. Published by ESG (www.electrochemsci.org). This article is an open access article distributed under the terms and conditions of the Creative Commons Attribution license (http://creativecommons.org/licenses/by/4.0/). 